\title{
Radiation measurements at the German Antarctic Neumayer Station
}

Sigrid Wuttke, Gunther Seckmeyer, Otto Schrems, Gert Koenig-Langlo

Sigrid Wuttke, Gunther Seckmeyer, Otto Schrems, Gert Koenig-Langlo, "Radiation measurements at the German Antarctic Neumayer Station," Proc. SPIE 5886, Ultraviolet Ground- and Space-based Measurements, Models, and Effects V, 588608 (18 August 2005); doi: 10.1117/12.616352 


\title{
Radiation Measurements at the German Antarctic Neumayer Station
}

\author{
Sigrid Wuttke $^{a}$ and Gunther Seckmeyer ${ }^{b}$ and Otto Schrems ${ }^{a}$ and Gert König-Langlo ${ }^{a}$ \\ ${ }^{a}$ Alfred Wegener Insititute for Polar and Marine Research, Am Handelshafen 12, Bremerhaven, \\ Germany; \\ ${ }^{b}$ Insititute for Meteorology and Climatology, University of Hannover, Herrenhäuser Str. 2, \\ Hannover, Germany
}

\begin{abstract}
During the austral summer 2003/04 the Institute for Meteorology and Climatology, University of Hannover, Germany, has deployed a newly developed spectroradiometric system at the permanent German Antarctic Neumayer Station $\left(70^{\circ} 39^{\prime} \mathrm{S}, 8^{\circ} 15^{\prime} \mathrm{W}\right)$. Aim of this campaign was to characterize the solar radiation conditions in an Antarctic environment. These are different from other areas of the Earth due to extremely high reflection of the ground (albedo). Relatively low cloud optical depths and ozone depletion further contribute to rather different radiation conditions compared to mid-latitudes. The investigation of these conditions will improve the understanding of the impact of climate change and ozone depletion in polar regions.

Spectral irradiance and radiance as well as luminance and spectral albedo have been measured in a wavelength range from 280 to $1050 \mathrm{~nm}$. With this set of radiation parameters it is assured that directional information of incident radiation parameters as well as the impact of surface albedo can be investigated.

Monitoring of radiation parameters is carried out by the Alfred Wegener Institute for Polar and Marine Research, Bremerhaven, Germany. Spectral irradiance from 290 to $400 \mathrm{~nm}$ has been measured since January 2001. UVB monitoring started in 1997. Broadband radiation parameters have been detected since 1981. Furthermore, the station participates in international networks initiated by the Word Climate Research Programme such as the Baseline Surface Radiation Network (BSRN) and the Global Atmospheric Watch (GAW). It is also a complementary site of the Network for the Detection of Stratospheric Change (NDSC).
\end{abstract}

Keywords: UV effects, spectroradiometric measurements, stratospheric change, NDSC, BSRN, Antarctica, spectral UV

\section{INTRODUCTION}

Radiation conditions in an Antarctic environment are different from other areas of the Earth due to extremely high reflection conditions of the ground. Relatively low cloud optical depths and ozone depletion further contribute to rather different radiation conditions compared to mid-latitudes. The characterization of the radiation conditions on an Antarctic ice shelf will improve the understanding of the impact of climate change and ozone depletion in polar regions.

Spectral irradiance is being monitored at a number of Antarctic sites for more than a decade now. ${ }^{1,2}$ At the permanent German Antarctic Neumayer Station (70 39' S, $8^{\circ} 15^{\prime} \mathrm{W}$, see Figure 1) spectral irradiance in the UVB (290 to $320 \mathrm{~nm}$ ) has been monitored since 1997. An additional instrument to cover the UVA (320 to $400 \mathrm{~nm}$ ) has been installed in January 2001. Both instruments are operated in the research mode of the Network for the Detection of Stratospheric Change (NDSC). Broadband radiation parameters have been detected since 1981. Furthermore, the station participates in international networks initiated by the Word Climate Research Programme such as the Baseline Surface Radiation Network (BSRN) and the Global Atmospheric Watch (GAW). It is also a complementary site of the NDSC.

Further author information: (Send correspondence to S. Wuttke)

S. Wuttke: E-mail: swuttke@awi-bremerhaven.de, Telephone: +494714831 1411

Ultraviolet Ground- and Space-based Measurements, Models, and Effects V,

edited by G. Bernhard, J. R. Slusser, J. R. Herman, W. Gao, Proc. of SPIE Vol. 5886

(SPIE, Bellingham, WA, 2005) · 0277-786X/05/\$15 · doi: 10.1117/12.616352

Proc. of SPIE 588608-1 


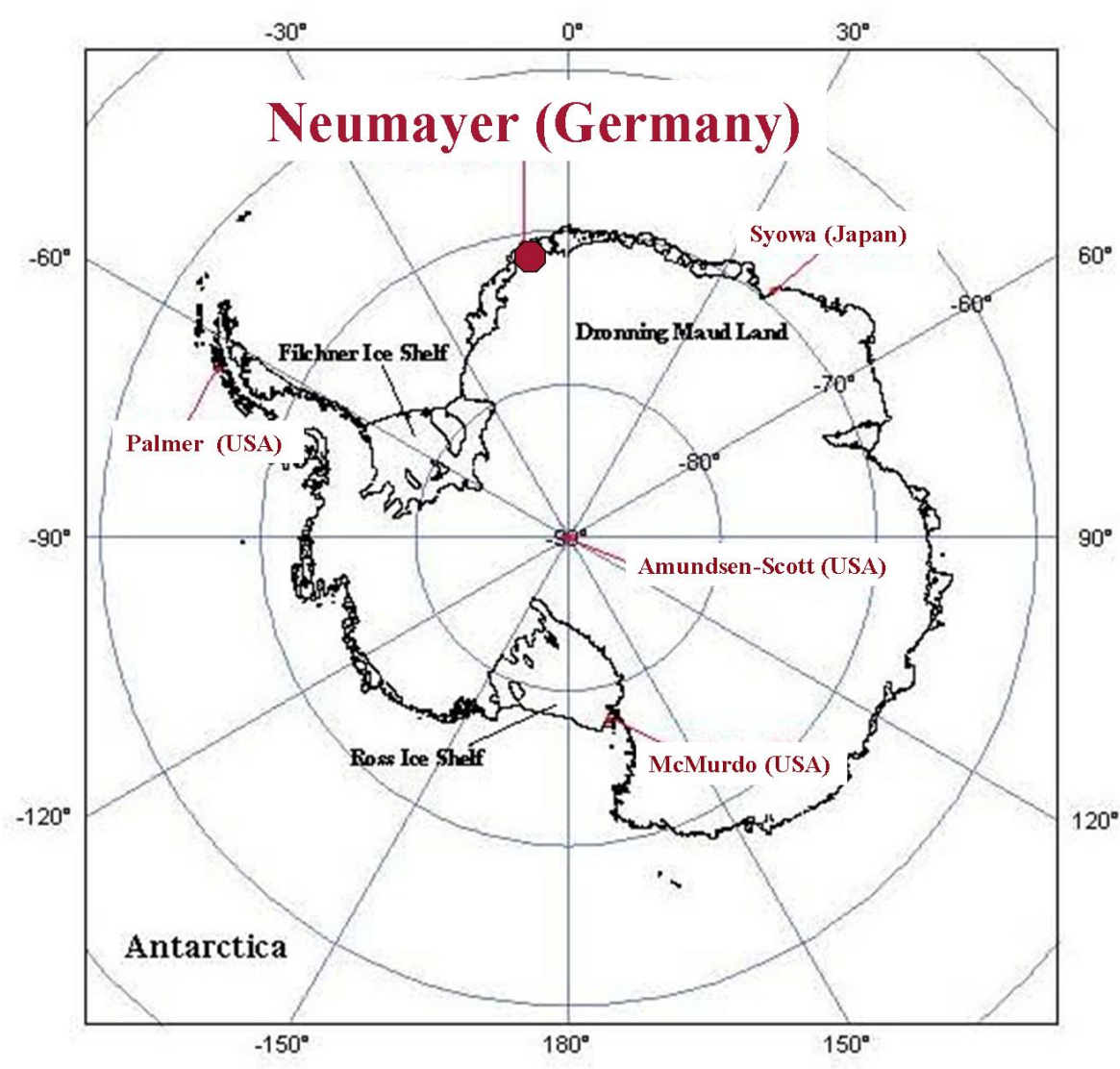

Figure 1. Map of Antarctica showing the main spectral UV monitoring stations.

In addition to these routine measurements, the Institute for Meteorology and Climatology (IMUK), University of Hannover, Germany, has deployed a newly developed spectroradiometric system at Neumayer during the austral summer 2003/04. Spectral irradiance and radiance as well as spectral albedo have been measured in a wavelength range from 280 to $1050 \mathrm{~nm}$. Luminance has also been measured. With this set of radiation parameters, we can investigate directional information of incident radiation parameters as well as the impact of surface albedo.

The combination of monitoring various incident radiation parameters and results of specific case studies provides valuable information in understanding Antarctic radiation conditions. This work focusses on introducing the radiation mesurements performed at Neumayer.

\section{RADIATION MEASUREMENTS AT NEUMAYER}

Neumayer is a favourable site to conduct radiation measurements. The main part of the station is underneath the snow surface. Only during the summer season, a few containers are set up on the station area to accommodate additional scientific and technical staff. Thus, obstructions of the measurements due to large buildings is minimised (see Figure 2). Since Neumayer is located on an ice shelf, the surrounding surface is very homogeneous representing a flat snow covered surface. Atka Bay is covered by sea ice most of the year.

The routine radiation measurements conducted at Neumayer will be presented first. In the next section the IMUK measurements during the summer campaign 2003/04 will be introduced, which served to investigate the effect of a high surface albedo on various downwelling radiation parameters. 


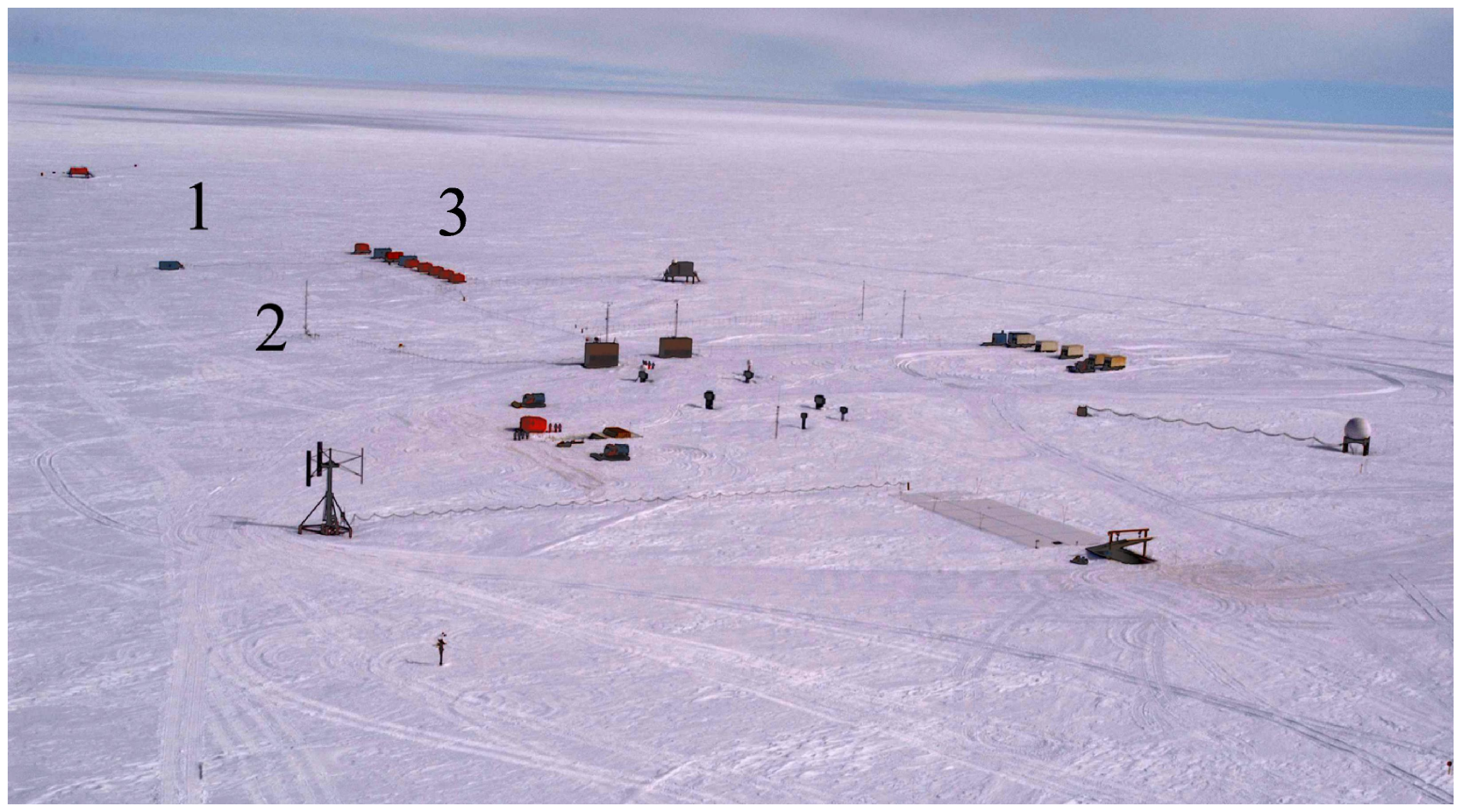

Figure 2. Neumayer Station photographed from an airplane during the summer season 2003/04. (1) Container with IMUK instruments. (2) AWI meteorological field site. (3) Summer camp [courtesy Johannes Käßbohrer].

\subsection{Routine Surface Radiation Measurements at Neumayer}

\subsubsection{Measurements of spectral UV irradiance}

Since 1997, AWI is monitoring spectral UVB irradiance (290 to $320 \mathrm{~nm}$ ) with a self-developed non-scanning spectroradiometer at Neumayer. The UVB-spectroradiometer is based on a Bentham DTM150 double monochromator and a Microchannel Photomultiplier Plate with 32 channels. An additional instrument was installed at Neumayer in January 2001 to also cover the UVA range (320 to $400 \mathrm{~nm}$ ) of the solar spectrum. This instrument contains a single monochromator as the dynamic range is low in the UVA compared to the UVB. The detector is a photodiode array with 256 detection channels. Single spectra can be sampled every second. In routine operation, they are stored as 5-minute averages. Figure 3 shows the AWI spectroradiometer during a mobile calibration at Neumayer. The mobile calibration serves to monitor the stability of the instrument during its deployment. The stability checks are performed with a seasoned $150 \mathrm{~W}$ lamp on a regular basis.

To be able to analyze the spectral UV irradiance in a meaningful way, it is important to also monitor parameters which affect the radiation levels at the surface or which provide additional information. The ancillary measurements performed at Neumayer are described in the following sections.

\subsubsection{BSRN measurements}

Since March 1982, broadband radiation parameters have been measured at Neumayer (see also http://www.awibremerhaven.de/MET/Neumayer/ ). The radiation signals are taken at one minute intervals and stored as averages over 10 minutes. They include:

- global irradiance (pyranometer CM11, Kipp+Zonen),

- reflected solar irradiance (pyranometer CM11, Kipp+Zonen),

- downward long-wave radiation (pyrradiometer, Lange), 


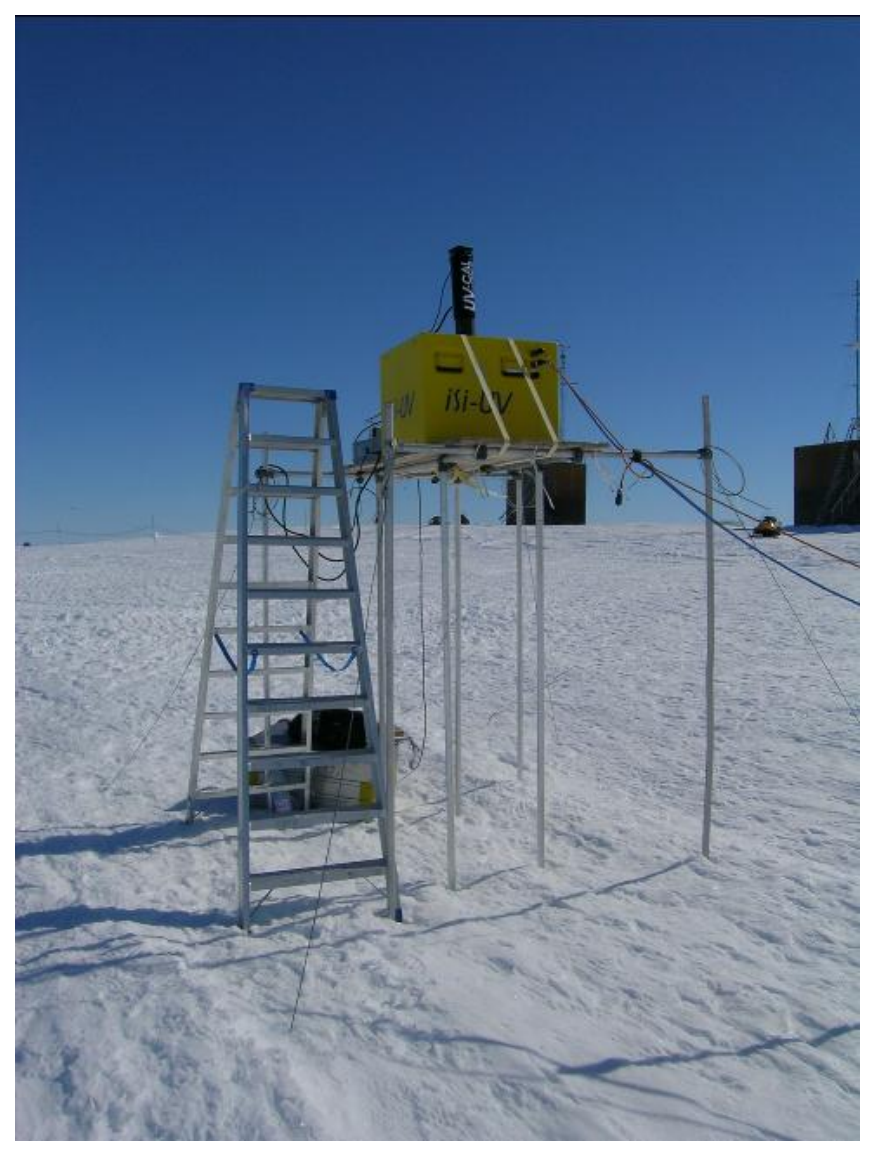

Figure 3. The AWI spectroradiometer during the process of mobile calibration.

- upward long-wave radiation (pyrradiometer, Lange),

- sunshine duration (Solar 111, Haenni).

In March 1992, the radiation measurements at Neumayer were extended in order to fulfil the standards of the Baseline Surface Radiation Network (BSRN). The pyrradiometer were replaced by pyrgeometers (PIR, Eppley), the averaging period was reduced to 1 minutes, and the following quantities are now measured in addition:

- diffuse sky irradiance (pyranometer CM11, Kipp+Zonen),

- direct solar irradiance (NIP, Eppley mounted on a sun tracker),

- OG1 (global > $530 \mathrm{~nm}$, pyranometer CM11, Kipp+Zonen),

- RG8 (global > $695 \mathrm{~nm}$, pyranometer CM11, Kipp+Zonen),

- UV (300 to $370 \mathrm{~nm}$, TUVR, Eppley).

The pyranometers and pyrgeometers are ventilated with slightly preheated air to minimize hoar frost problems and zero offsets during cloudless and windless conditions. The instruments were maintained continuously several times per day throughout the year. After one year of operation, they are re-calibrated at the German Weather Bureau according the World Radiometric Reference (WRR). Figure 4 shows the radiation field with all the broadband radiation parameters at Neumayer. 


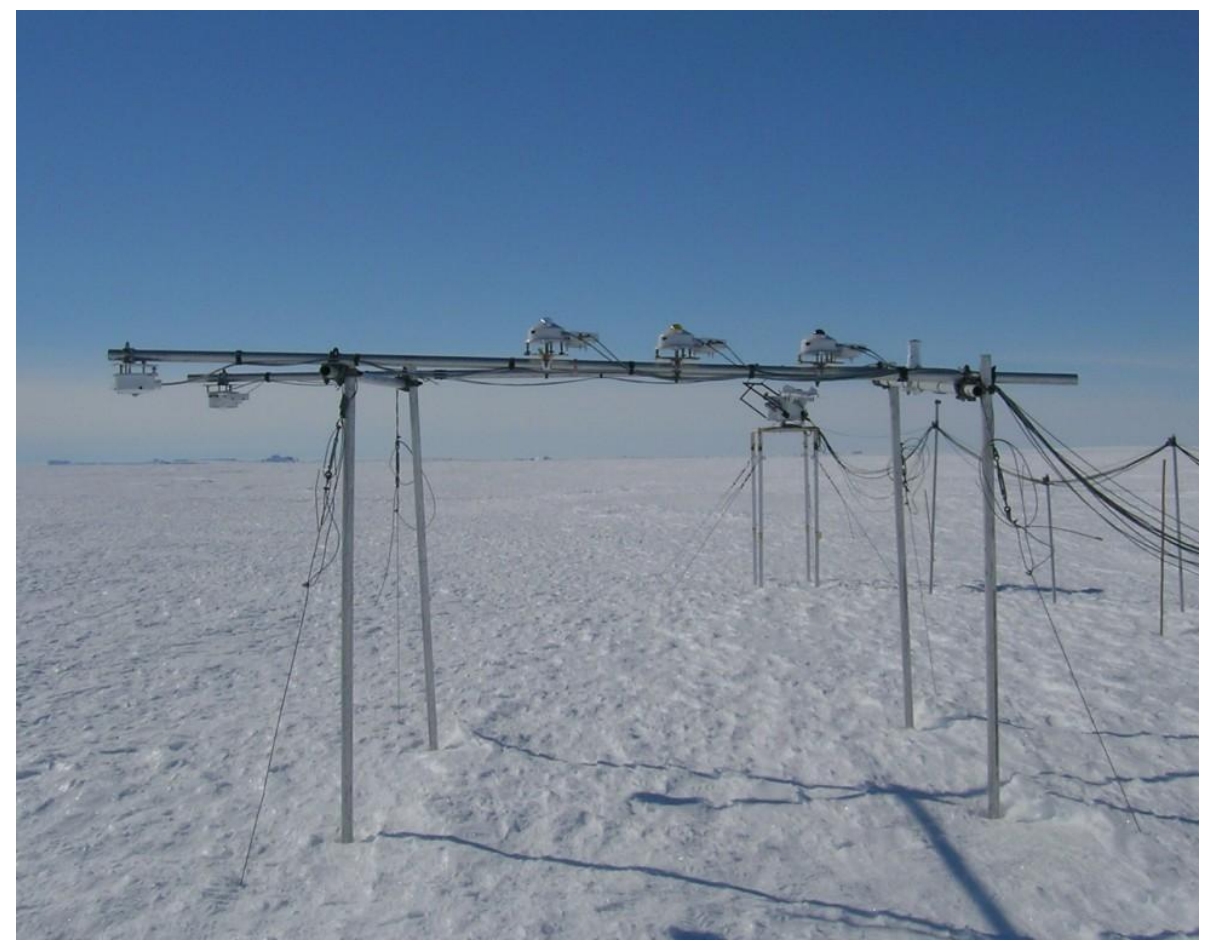

Figure 4. Field site with different broadband radiation sensors complying with the BSRN standards.

\subsubsection{Upper air soundings}

Since 1992, regular ozone soundings have been performed using ECC 5A/6A sensors mounted on Vaisala radiosondes (Types RS80 and RS90). Ozone profiles up to a height of $35 \mathrm{~km}$ are obtained on a weekly basis. The ozone depletion occuring each Antarctic spring can be recognized in the time series (see http://www.awibremerhaven.de/MET/Neumayer/ozone_his.html). During the ozone depletion periode, the sounding rate is increased from 1 sounding per week up to 2 to 3 soundings per week.

Meteorological upper air soundings are carried out routinely once a day between at 12 UTC. They include profile measurements of pressure, temperature, relative humidity, and wind vector. The data is coded (FM35Temp) and transferred directly via e-mail to the Global Telecommunication System (GTS) where it contributes to weather forecasting.

\subsubsection{Determination of aerosols with a sun photometer}

Sun photometer measurements to retrieve the aerosol optical depth are performed whenever the sun is located between $40^{\circ}$ and $20^{\circ}$ above the horizon and is not hidden by clouds. ${ }^{3}$ The instrument has 17 channels in the wavelength range from 351 to $1062 \mathrm{~nm}$ with a full width at half maximum ranging from 5 to $15 \mathrm{~nm}$. In addition to the aerosol optical depth in the visible and infrared, the asymmetry parameter and the real part of the refractive index can be retrieved under daylight conditions based on sky brightness measurements.

\subsection{IMUK Measurements}

In order to investigate the effect of the high surface albedo prevailing on an Antarctic ice shelf on various downwelling radiation parameters, the Institute of Meteorology and Climatology of the University of Hannover has deployed various spectral and broadband instruments at Neumayer during the summer campaign of 2003/04. A summary of the radiation parameters measured during the IMUK summer campaign at Neumayer as well as a list of instruments is given in Table 1.

The main instruments are the skyscanner and the spectroradiometer. The skyscanner was specifically developed by Czibula \& Grundmann (http://www.photo-meter.com) for operation in harsh climate conditions. 
Table 1. Summary of the radiation data collected during the Antarctic campaign at Neumayer in the austral summer 2003/04.

\begin{tabular}{|l|l|l|}
\hline Parameter & Instrument & Amount of data \\
\hline Spectral irradiance & $\begin{array}{l}\text { Spectroradiometer } \\
\text { with cosine diffuser }\end{array}$ & $\begin{array}{l}\text { 2725 spectra } \\
\text { on 86 days }\end{array}$ \\
\hline Spectral albedo & $\begin{array}{l}\text { Spectroradiometer } \\
\text { with cosine diffuser }\end{array}$ & $\begin{array}{l}\text { 1026 spectra of up- and down- } \\
\text { welling irradiance on 12 days }\end{array}$ \\
\hline $\begin{array}{l}\text { Broadband } \\
\text { UV albedo }\end{array}$ & SL501 & $\begin{array}{l}5 \text {-minute means } \\
\text { on 15 days }\end{array}$ \\
\hline Luminance & Skyscanner & $\begin{array}{l}\text { Collected every minute } \\
\text { on 88 days }\end{array}$ \\
\hline Spectral radiance & $\begin{array}{l}\text { Spectroradiometer } \\
\text { with Skyscanner }\end{array}$ & 336 spectra on 20 days \\
\hline $\begin{array}{l}\text { Erythemal } \\
\text { irradiance }\end{array}$ & SL501 & $\begin{array}{l}\text { 1-minute means } \\
\text { on 90 days }\end{array}$ \\
\hline Global irradiance & Pyranometer & $\begin{array}{l}1-\text { minute means } \\
\text { on 100 days }\end{array}$ \\
\hline $\begin{array}{l}\text { Total ozone } \\
\text { column }\end{array}$ & $\begin{array}{l}\text { Microtops Sun } \\
\text { Photometer }\end{array}$ & $\begin{array}{l}119 \text { total ozone columns } \\
\text { on 37 days }\end{array}$ \\
\hline
\end{tabular}

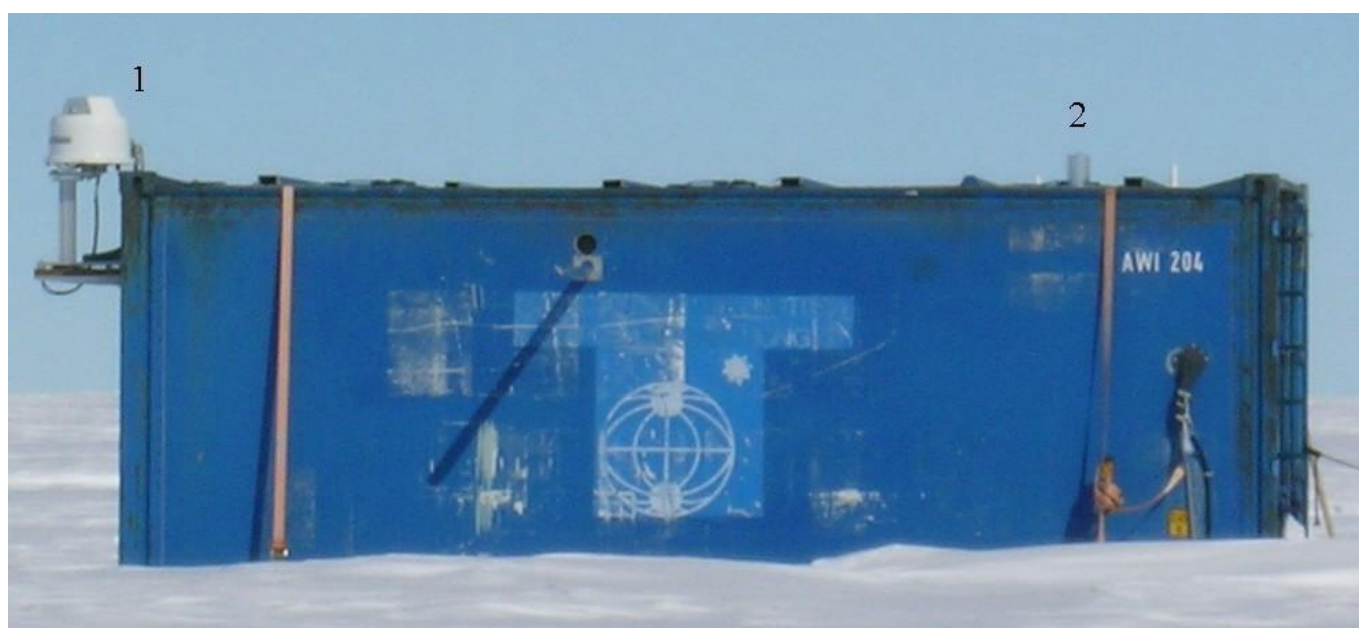

Figure 5. Container for radiation measurements during the summer campaign 2003/04. On the left, the skyscanner (1) is mounted. The metal tube (2) on the right part of the roof holds the input optics for spectral irradiance measurements.

Figure 5 shows the container with all the IMUK instruments. The container was provided by AWI and served as weather protection for the spectroradiometer, data loggers and operating personal computers.

The spectroradiometer has been newly developed at IMUK. It covers the wavelength range from 290 to $1050 \mathrm{~nm}$. State-of-the-art procedures for quality control and assurance have been developed and applied. It complies with the stringent requirements of the $\mathrm{NDSC}^{4}$ and has recently been accredited as a mobile NDSC instrument.

\section{SPECTRAL IRRADIANCE IN 2003/04}

As example results spectral irradiance measurements performed by IMUK are presented. They have been performed in a wavelength range from 280 to $500 \mathrm{~nm}$ in steps of $0.25 \mathrm{~nm}$ and 501 to $1050 \mathrm{~nm}$ in steps of $1 \mathrm{~nm}$. Spectra have been recorded 24 hours per day. It takes about 35 minutes to record a spectrum of irradiance in 


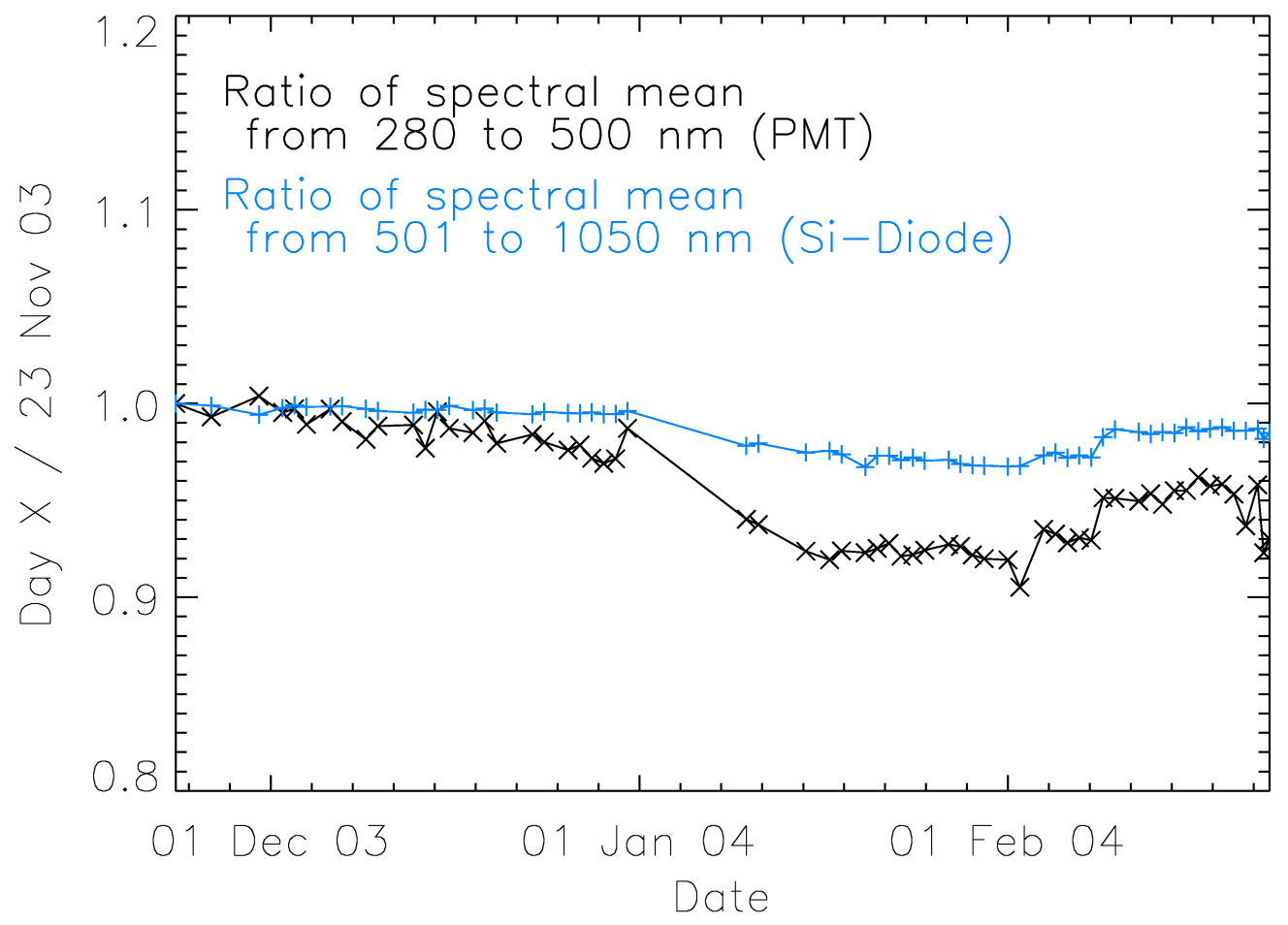

Figure 6. Time series of the stability of the spectroradiometer over the complete duration of the campaign with the diffuser for irradiance measurements as input optics. The $100 \mathrm{~W}$ lamp measurements of each day have been divided by the lamp measurements on 23 November 2003.

these wavelength steps, this amounts to about 42 spectra per day. To guarantee a reliable quality of the spectral data various QC procedures have been followed on a regular schedule. The most important tasks include checks of the radiometric and wavelength stability.

\subsection{Radiometric and wavelength stability}

$100 \mathrm{~W}$ quartz halogen lamps have been deployed inside a portable field calibrator in order to obtain knowledge about the radiometric stability over time. ${ }^{5}$ Stability checks have been conducted daily. The stability time series are shown in Figure 6.

Two different time series are illustrated; one shows the stability for the PMT, the second depicts the stability for the silica diode. They are shown separately for each detector, because each one can behave differently over time. Lamp measurements have been related to the first day of lamp measurements within the campaign. It can be seen in Figure 6 that the silica diode shows a more stable performance than the PMT. The spectroradiometric system is stable to within $2 \%$ considering the silica diode. The change in responsivity considering the PMT is larger with $9 \%$. For both detectors, the responsivity decreases over time. To account for this loss, the each day's lamp measurements are considered for the absolute calibration of spectral irradiance. No stability checks have been performed during the first ten days of January 2004 because albedo measurements have been performed with the entrance optics mounted to the metal rods during this period.

During the campaign, the wavelength shift is monitored daily by applying the algorithm SHICrivm ${ }^{6}$ to the spectral irradiance data. The wavelength shift varies over the course of the day with $0.03 \mathrm{~nm}$. The absolute wavelength shift for all wavelengths is $0.05 \mathrm{~nm}$ from the nominal wavelength. The shape of the wavelength shift shows a periodic structure. This structure and magnitude does not change over the complete course of the campaign. 


\subsection{Model comparison}

Figure 7 shows the ratio of modelled to measured irradiance in dependence on SZA for eight different wavelengths. Spectral irradiance has been modelled with UVSPEC. ${ }^{7}$ The results of this comparison between modelled and measured irradiance will serve

- as a tool for controlling the quality of the measured data and

- to assess whether the spectral irradiance measured within this campaign is useful for a model evaluation.

For this comparison, only cloudless situations have been considered. A situation is considered cloud free when the AWI sunshine duration indicator showed the signal for unobscured sun and when no clouds have been detected by the AWI LIDAR. Model input parameters comprise

- the SZA dependent on wavelength according to the scan time,

- the measured spectral snow albedo from the cloudless afternoon of 4 January 2004,

- the total ozone column from the Total Ozone Mapping Spectrometer (TOMS) (ftp://jwocky.gsfc.nasa.gov/pub/eptoms/data/overpass/OVP323_ept.txt),

- no aerosols, and

- subarctic atmospheric profiles.

Instead of TOMS ozone data, Microtops ozone data could have been used. Reasons for this decision are discussed in the next Section. The assumption of zero aerosols is justified as the Antarctic atmosphere is known to be very clean. ${ }^{8}$ Antarctic atmospheric profiles would have been favourable, but they are not contained in the standard distribution of libRadtran (http://www.libradtran.org).

The deviation from unity is lowest for $350 \mathrm{~nm}$ with deviations of $\pm 10 \%$ for all SZA. The deviation at 320 and $400 \mathrm{~nm}$ is also low within $\pm 15 \%$, but mostly lower. At $305 \mathrm{~nm}$ large deviations are seen. They range from -30 to $+100 \%$. For the three largest wavelengths $(695,800$, and $1000 \mathrm{~nm})$ a clear dependence on SZA can be observed. The ratio between measurement and model increases the larger the SZA, and reaches up to $+80 \%$ for an SZA of $88^{\circ}$.

\section{DISCUSSION}

The comparison of modelled to measured irradiance shows a dependency on SZA for wavelengths larger than $500 \mathrm{~nm}$ (see Figure 7). This behaviour can be explained by the non-ideal cosine response of the irradiance input optics. The larger the wavelength the larger the portion of the direct relative to the diffuse irradiance. ${ }^{9}$ Radiation at short wavelengths is scattered much more according to the inverse wavelength dependence of Rayleigh scattering. ${ }^{10}$ Further, the larger the SZA the more pronounced is the deviation of the input optics from the ideal cosine response, even though the diffuser is shaped. ${ }^{11}$

The larger deviation between model and measurement at $305 \mathrm{~nm}$ can be explained by uncertainties of the total ozone column. Originally, the Mictrotops total ozone column was intended to be used because previous investigation have shown an excellent performance of the Microtops also for high latitudes. It can be seen in ${ }^{5}$ that channel 2 of some specific Microtops instruments underestimates the total ozone column compared to TOMS by $8 \%$ on average. This is in accordance with results stated by ${ }^{12}$ that the TOMS data overestimate the total ozone column by 4 to 10\%. Despite all these arguments in favour of Microtops data, TOMS total ozone has been used. If a lower ozone column had been used as an input into UVSPEC the deviation between measurement and model would be lower. 

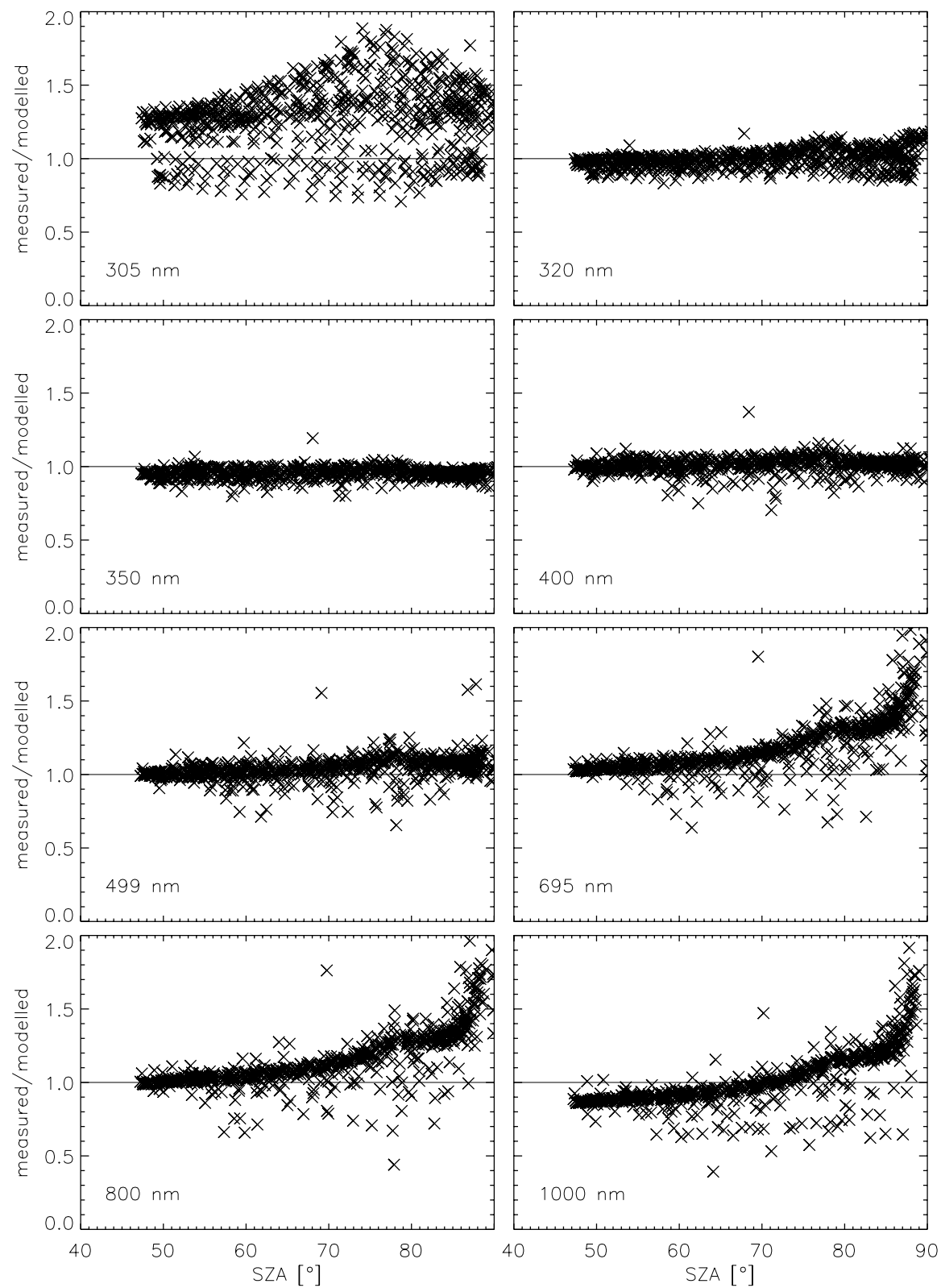

Figure 7. Ratio of modelled to measured irradiance in dependence of SZA for different wavelengths. The deviation from unity is lowest at wavelengths in the UVA, with no dependency on SZA. For 695, 800, and 1000 nm the ratio increases with increasing SZA. 


\section{CONCLUSION}

The radiation measurements at the permanent German Antarctic Station Neumayer have been introduced. Infrastructure and a number of ancillary measurements provide a good basis for studies of spectral UV irradiance. It has been shown that only specially designed and well-maintained instruments can deliver data with sufficient quality for spectral radiation meaurements in an Antarctic environment.

\section{ACKNOWLEDGMENTS}

This work has been supported by the Deutsche Forschungsgemeinschaft (DFG) and the Alfred Wegener Insitute for Polar and Marine Research.

\section{REFERENCES}

1. G. Bernhard, C. R. Booth, and J. C. Ehramjian, "Version 2 data of the national science foundation's ultraviolet radiation monitoring network: South pole," J. Geophys. Res. 109, p. Doi: 10.1029/2004JD004937, 2004.

2. T. Takao, M. Aono, T. Kishi, K. Sakurai, O. Ijima, M. Takakwa, O. Narita, and M. Shitamichi, "Ultraviolet spectral irradiance observations at syowa station, antarctica 1991-1996," The Geophysical Magazine Series 2 3(3), pp. 95-107, 1999.

3. A. Herber, L. W. Thomason, H. Gernandt, U. Leiterer, D. Nagel, K.-H. Schulz, J. Kaptur, T. Albrecht, and J. Notholt, "Continuous day and night aerosol optical depth obersvations in the arctic between 1991 and 1999," J. Geophys. Res. 107(D10), p. DOI 10.1029/2001JD000536, 2002.

4. S. Wuttke, G. Bernhard, J. Ehramjian, R. McKenzie, P. Johnston, M. O'Neill, and G. Seckmeyer, "New spectroradiometers complying with the ndsc standards," J. Atmos. Oceanic Technol., p. accepted, 2005.

5. S. Wuttke, Radiation Conditions in an Antarctic environment. PhD thesis, Universität Hannover, 122004.

6. H. Slaper, H. A. J. M. Reinen, M. Blumthaler, M. Huber, and F. Kuik, "Comparing ground-level spectrally resolved solar uv measurements using various instruments: A technique resolving effects of wavelength shift and slit width," Geophys. Res. Lett. 20, pp. 2721-2724, 101995.

7. B. Mayer and A. Kylling, "Thechnical note: The libradtran software package for radiative transfer calculations - description and examples of use," Atmos Chem Phys Discuss 5, pp. 1319-1381, 2005.

8. C. Piel, "Variability of chemical and physical parameters of aerosol in the antarctic troposphere," Reports on Polar and Marine Research 476, Alfred Wegener Institute for Polar and Marine Research, Bremerhaven, Germany, 2004.

9. WMO, Scientific Assessment of Ozone Depletion: 2002, Global Research and Monitoring Project - Report No. 47, Geneva, 2003.

10. J. Lenoble, Atmospheric Radiative Transfer, A. Deepak Publishing, Hampton, VA, 1993.

11. G. Bernhard and G. Seckmeyer, "New entrance optics for solar spectral uv measurements," Photochem. Photobiol. 65, pp. 923-930, 1997.

12. G. Bernhard, C. Booth, and J. Ehramjian, "Comparison of measured and modeled spectral ultraviolet irradiance at antarctic stations used to determine biases in total ozone data from various sources," in Ultraviolet Ground and Space-Based Measurements, Models and Effects, J. Slusser, J. Herman, and W. Gao, eds., Proceedings of SPIE 4482, pp. 115-126, (Bellingham, Washington, D.C.), 2002. 